\title{
Glucose metabolism is inhibited by caspases upon the induction of apoptosis
}

\author{
LA Pradelli ${ }^{1,2}$, E Villa ${ }^{1,2}$, B Zunino ${ }^{1,2,3}$, S Marchetti ${ }^{2,4}$ and J-E Ricci, ${ }^{* 1,2,3}$
}

Rapidly proliferating cells, such as cancer cells, have adopted aerobic glycolysis rather than oxidative phosphorylation to supply their energy demand; this phenomenon is known as 'the Warburg effect'. It is now widely accepted that during apoptosis the loss of energy production, orchestrated by caspases, contributes to the dismantling of the dying cell. However, how this loss of energy production occurs is still only partially known. In the present work, we established that during apoptosis the level of cellular ATP decreased in a caspase-dependent manner. We demonstrated that this decrease in ATP content was independent of any caspase modification of glucose uptake, ATP consumption or reactive oxygen species production but was dependent on a caspase-dependent inhibition of glycolysis. We found that the activity of the two glycolysis-limiting enzymes, phosphofructokinase and pyruvate kinase, were affected by caspases, whereas the activity of phosphoglycerate kinase was not, suggesting specificity of the effect. Finally, using a metabolomic analysis, we observed that caspases led to a decrease in several key metabolites, including phosphoserine, which is a major regulator of pyruvate kinase muscle isozyme activity. Thus, we have established that during apoptosis, caspases can shut down the main energy production pathway in cancer cells, leading to the impairment in the activity of the two enzymes controlling limiting steps of glycolysis.

Cell Death and Disease (2014) 5, e1406; doi:10.1038/cddis.2014.371; published online 4 September 2014

The activation of caspase proteases is fundamental to apoptotic cell death. Once activated, 'executioner' caspases, such as caspase-3, orchestrate the rapid dismantling of the cell. Apoptosis is a process that requires energy. ATP is required for caspase activation, enzymatic hydrolysis of molecules, bleb formation and chromatin condensation. ${ }^{1}$ However, in contrast to normal differentiated cells, which rely primarily on mitochondrial oxidative phosphorylation (OXPHOS) to generate the energy needed for cellular processes, most cancer cells instead rely on aerobic glycolysis, a phenomenon termed 'the Warburg effect'. ${ }^{2}$ This phenomenon induces an increase of glucose consumption and provides the basis for the most sensitive and specific imaging technique available for the diagnosis and staging of solid cancers: positron emission tomography scan of $2-\left[{ }^{18} \mathrm{~F}\right]$ fluoro-2-deoxy-glucose uptake.

Glycolysis is a series of metabolic processes, catalyzed by one of ten specific enzymes, by which 1 mole of glucose is catabolized to 2 moles of pyruvate and 2 moles of NADH with a net gain of 2 moles of ATP. Glycolysis is tightly regulated by the three allosteric enzymes, hexokinase (HK), phosphofructokinase-1 (PFK) and pyruvate kinase (PK), which catalyze the irreversible steps. HK, the first enzyme of glycolysis, phosphorylates glucose into glucose-6-phosphate, preventing the molecule from leaking out of the cell.
The most complex control over glycolytic flux is attributed to PFK, which catalyzes the phosphorylation of fructose6-phosphate to fructose-1,6-bisphosphate using MgATP as the phosphoryl donor. ${ }^{3}$ PFK1 is stimulated by fructose-2, 6-bisphosphate (F-2,6-BP), ADP/AMP and ammonium ions, whereas citrate and ATP act as strong inhibitors.

Another limiting step is controlled by the final enzyme of the glycolytic pathway, PK. Four PK isoforms exist in mammals; the $L$ and $R$ isoforms are expressed in liver and red blood cells, respectively, whereas the $\mathrm{M} 1$ (muscle) isoform is expressed in most adult tissues, and tumor cells have been shown to mainly express the embryonic M2 isoform. ${ }^{4}$

In the presence of oxygen, mitochondria can oxidize pyruvate and $\mathrm{NADH}$, resulting in the production of 36 moles of ATP (OXPHOS). However, even under normoxic conditions, most cancer cells will not perform OXPHOS but will instead reduce pyruvate to lactate. Although, aerobic glycolysis is an inefficient way to generate ATP, aerobic glycolysis seems to confer certain advantages to cancer cells, such as the ability to generate several intermediates that can be used by other metabolic pathways to produce nucleotides or lipids. ${ }^{5}$ However, the exact nature of the benefits conferred by glycolysis is still under debate.

It is well established that caspase activation relies on ATP to proceed. However, it has been previously suggested that upon induction of apoptosis, ATP levels dramatically fall in a

\footnotetext{
${ }^{1}$ Inserm, U1065, Centre Méditerranéen de Médecine Moléculaire (C3M), équipe 'contrôle métabolique des morts cellulaires', Nice, France; ${ }^{2}$ Faculté de Médecine, Université de Nice-Sophia-Antipolis, Nice, France; ${ }^{3}$ Département d'Anesthésie Réanimation, Centre Hospitalier Universitaire de Nice, Nice, France and ${ }^{4}$ Inserm, U1065, Centre Méditerranéen de Médecine Moléculaire (C3M), équipe 'mort cellulaire, différenciation et cancer', Nice, France

*Corresponding author: J-E Ricci, Inserm U1065, Centre Méditerranéen de Médecine Moléculaire (C3M), équipe 'mort cellulaire, différenciation et cancer', équipe 3, 151 route de St Antoine de Ginestière, BP 23194, 06204 Nice, France. Tel: +33 48906 4304; Fax: +33 48906 4221; E-mail: ricci@ unice.fr

Abbreviations: Act-D, actinomycin D; R5P, ribose-5-phosphate; P-Ser, phospho-serine; G6P, glucose-6-phosphate; F6P, fructose-6-phosphate; 2-PGA, 2-phosphoglycerate; PEP, phosphoenolpyruvate; HK, hexokinase; PGI, phosphoglucoisomerase; PFK, phosphofructokinase; GAPDH, glyceraldehyde 3-phosphate dehydrogenase; PGK, phosphoglycerate kinase; PK, pyruvate kinase; ROS, reactive oxygen species; LDH, lactate desydrogenase

Received 19.5.14; revised 22.7.14; accepted 28.7.14; Edited by C Munoz-Pinedo
} 
caspase-dependent manner. ${ }^{6}$ In the present report, we explored the role of caspases on glycolysis, the main energy-producing pathway used by cancer cells.

\section{Results}

Caspase-dependent decrease in ATP is observed in glycolytic cells upon the induction of apoptosis. To characterize the main source of ATP production in HeLa cells, we used a potent and specific complex $\mathrm{V}$ inhibitor (oligomycin D). Oligomycin D did not modify ATP production underlying the glycolytic nature of these cells. We verified that oligomycin D treatment was efficient, as it led to a decrease in ATP content when the cells were forced to use mitochondria to produce energy (in a no glucose + pyruvate condition, Figure 1a). To examine how glycolytic ATP was modulated upon the induction of apoptosis, we treated HeLa cells with various cell death inducers (Figures $1 \mathrm{~b}$ and $c$ ) in the presence or absence of a pan-caspase inhibitor (qVD-OPH). The ATP levels decreased in these cells upon apoptosis induction. The DEVDase activities, reflecting caspase activation upon treatment, are presented in Figure 1d. Strikingly, the caspase inhibition was very efficient in preventing cell death, caspase activity and most of the observed decrease in ATP content (Figures 1b-d).

The observed decrease in ATP during cell death was not mediated through caspase regulation of glucose import, ATP consumption or reactive oxygen species production but via glycolysis regulation. Several hypotheses could explain the decrease in ATP production observed in glycolytic cells during apoptosis. First, caspases could decrease glucose import and therefore inhibit glycolysis. To test this hypothesis, we monitored glucose import using radiolabeled 2-deoxy-D-glucose (2DG). As presented in Figure $2 \mathrm{a}$, no decrease in glucose import was observed in a

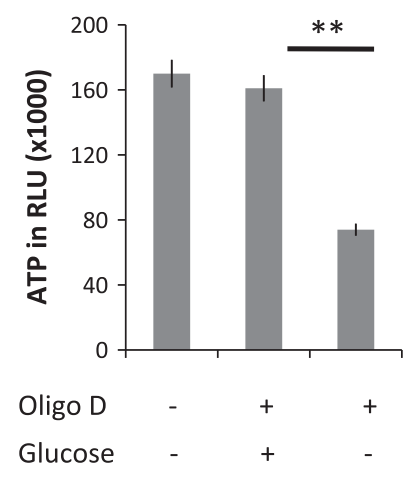

C

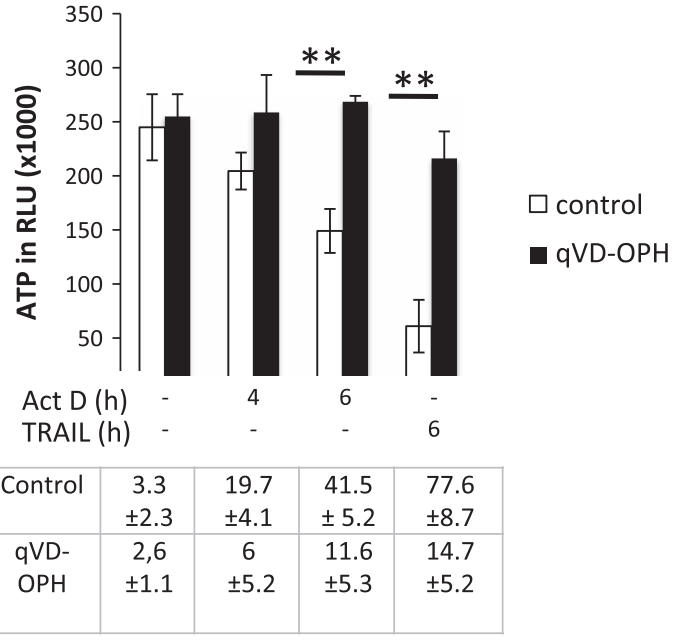

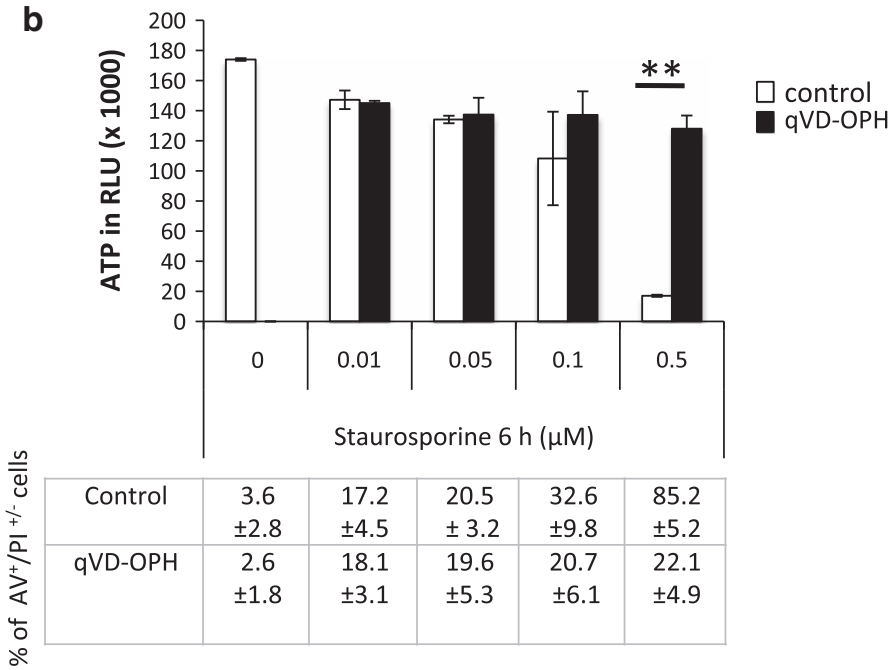

d

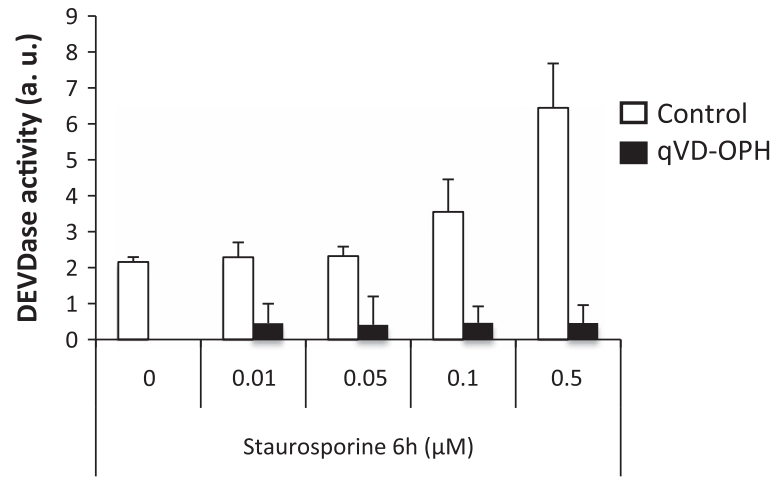

Figure 1 The ATP decrease during apoptosis is caspase dependent. (a) HeLa cells were plated in control media and were then either deprived of glucose for $16 \mathrm{~h}$ and/or incubated in the presence of oligomycin D (oligo D, $10 \mathrm{ng} / \mathrm{ml}$ ) $1 \mathrm{~h}$ before ATP measurement. (b) HeLa cells were plated in 96-well plates and treated as indicated with staurosporine with or without qVD-OPH $(20 \mu \mathrm{M})$. ATP was then measured, and the results are expressed in relative luminescence units. (c) HeLa cells were treated with $1 \mu \mathrm{M}$ actinomycin $\mathrm{D}(\mathrm{Act} \mathrm{D})$ or with $100 \mathrm{ng}$ of recombinant TRAIL as indicated and analyzed in $\mathbf{a}$. Tables in $\mathbf{b}$ and $\mathbf{c}$ represent the \% of annexin $\mathrm{V} / \mathrm{propidium}$ iodide $\left(\mathrm{AV}^{+} / \mathrm{PI}^{+1-}\right)$ cells in indicated conditions. (d) HeLa cells were treated as in $\mathbf{b}$ and DEVDase activity was measured with or without qVD-OPH $(20 \mu \mathrm{M}) .{ }^{* \star} P<0.005$ 
a

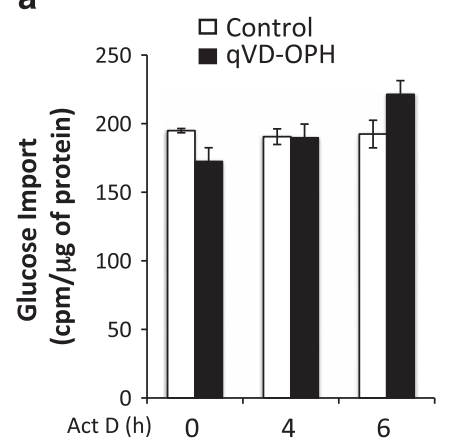

b

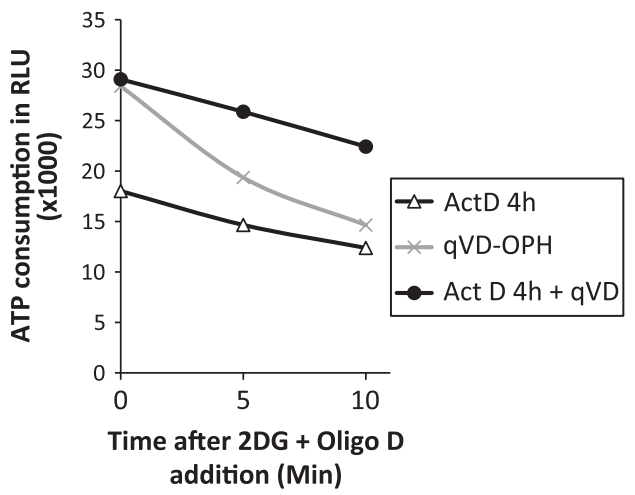

C

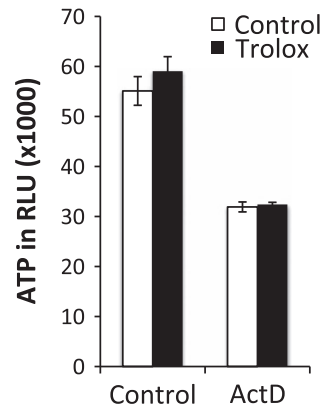

Figure 2 There is no modification of glucose import or ATP consumption during apoptosis. HeLa cells were treated with $1 \mu \mathrm{M}$ actinomycin D with or without qVD-OPH $(20 \mu \mathrm{M})$ for the indicated time. (a) Glucose import and (b) ATP consumption were measured as indicated in the Materials and Methods section. (c) HeLa cells were preincubated with $50 \mu \mathrm{M}$ Trolox (a ROS scavenger) before a 6-h treatment with $1 \mu \mathrm{M}$ actinomycin D. ATP was then measured as in Figure 1a

dying cells, thus excluding the possibility that decreased glucose import inhibits glycolysis. A second hypothesis is that ATP consumption may increase significantly during apoptosis. We therefore, treated cells with actinomycin D (Act D) ( \pm qVD-OPH) for $4 \mathrm{~h}$. Following this treatment, the cells were incubated with inhibitors of ATP production, that is, 2DG to inhibit glycolysis and oligomycin $D$ to prevent any ATP production through the mitochondria, and ATP levels were monitored within minutes. As expected, we observed a significant decrease in the ATP content in the control condition (qVD-OPH alone), representing the basal ATP consumption in cells. Therefore, even if Act $D$ treatment led to a significant reduction in ATP consumption, this reduction could not account for the global decrease in ATP content observed during apoptosis, as qVD-OPH could not protect it. Of note, the amount of luminescence observed at the beginning of the experiment (on the axes at $0 \mathrm{~min}$ ) reflects the reduction of ATP content and the protective effect of qVD-OPH (as in Figure 1). Altogether, these data indicate that the overall ATP consumption was not modulated by caspases. A third hypothesis is that ROS produced upon the induction of apoptosis could impair glycolysis. ROS production is frequently a key player in apoptosis; however, its exact role remains controversial. ${ }^{7}$ As massive ROS production leads to the modulation of the activities of some glycolytic enzymes and as caspase inhibitors are very efficient in preventing ROS production during cell death, ${ }^{8}$ we analyzed the effect of a ROS scavenger (Trolox) on ATP production during apoptosis. As presented in Figure 2c, Trolox alone had no effect on ATP production under basal conditions. In addition, even if the scavenger was very efficient at inhibiting ROS production (not shown), the scavenger could not prevent the decrease in ATP induced by Act D. Thus, the decrease in ATP observed in glycolytic cells during apoptosis was caspase dependent but ROS independent.

The last hypothesis was whether caspases could directly affect the glycolysis pathway. We therefore measured the glycolytic rate of cells upon the induction of apoptosis. The glycolytic rate can be determined by analyzing the conversion of $\left[5^{-3} \mathrm{H}\right]$ glucose to ${ }^{3} \mathrm{H}_{2} \mathrm{O}$. The ${ }^{3} \mathrm{H}$ on $\mathrm{C} 5$ of glucose is released in the form of ${ }^{3} \mathrm{H}_{2} \mathrm{O}$ during the second to last step of glycolysis when 2-phosphoglycerate (2-PGA) is converted to phosphoenolpyruvate (PEP) by enolase (see Figure 6). As observed in Figure $3 a$, the glycolytic rate was significantly decreased in a caspase-dependent manner during apoptosis, an effect that could be prevented by qVD-OPH. This result suggested that glycolysis was impaired between glucose and phosphoenolpyruvate production (Figure 6). Finally, the impact of caspases on glycolysis was confirmed by measuring the decrease of lactate production, a final by-product of glycolysis in cancer cells (Figure $3 b$ ). Altogether, our results indicated that the decrease in ATP content, observed during apoptotic cell death, was neither correlated with a decrease in glucose import nor with an increase in ATP consumption or ROS production but rather with an impairment of the glycolysis pathway by caspases.

PFK and PK but not phosphoglycerate kinase activities are impaired by caspases. Because glycolysis is mainly regulated by $\mathrm{PFK}$ and $\mathrm{PK}$, we therefore measured their enzymatic activity in apoptotic cells \pm qVD-OPH. We observed that both enzymatic activities were impaired by $>50 \%$ upon the induction of apoptosis in a caspasedependent manner (Figures $4 a$ and $b$ ). To verify whether the decrease in the activity of these glycolytic enzymes was a general feature of apoptosis, we measured the activity of the non-rate-limiting enzyme, PGK. As presented in Figure 4c, PGK activity was not affected under the same conditions, suggesting that inhibition was specific. Altogether, we demonstrated that caspases could affect the activity of a couple of rate-limiting enzymes of this pathway.

Caspases decrease the production of several metabolites during apoptosis. To better understand how caspases control the activity of key glycolytic enzymes and therefore glycolysis, we performed a metabolomic analysis of control and apoptotic HeLa cells ( \pm qVD-OPH). As presented in Figure 5a, we confirmed the caspase-dependent decrease in ATP content of the cells upon the induction of apoptosis. We also observed that ADP was modulated in a similar manner upon the induction of apoptosis.

Unfortunately, we could not quantify all the glycolytic intermediates, but we could establish that neither glucose6-phosphate nor fructose-6-phosphate were significantly 
a

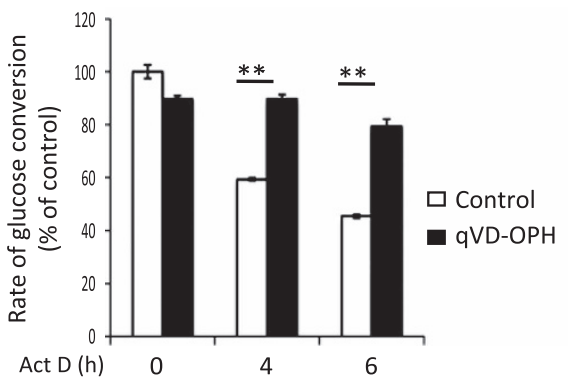

b

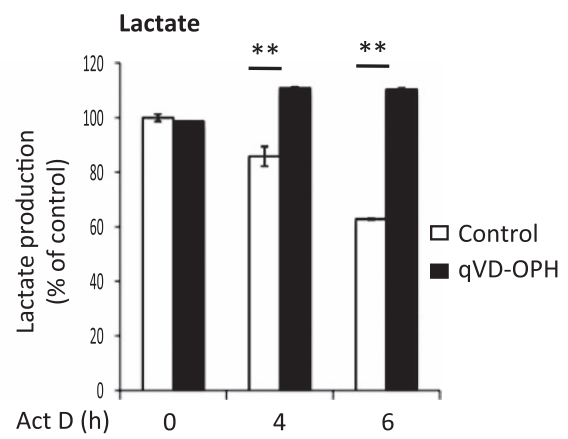

Figure 3 Caspase-dependent inhibition of glycolytic flux and lactate production. (a) The glycolytic rate and (b) lactate production were measured after treatment with $1 \mu \mathrm{M}$ actinomycin $\mathrm{D}( \pm \mathrm{qVD}-\mathrm{OPH})$ for the indicated times. See the Materials and Methods section for details

a

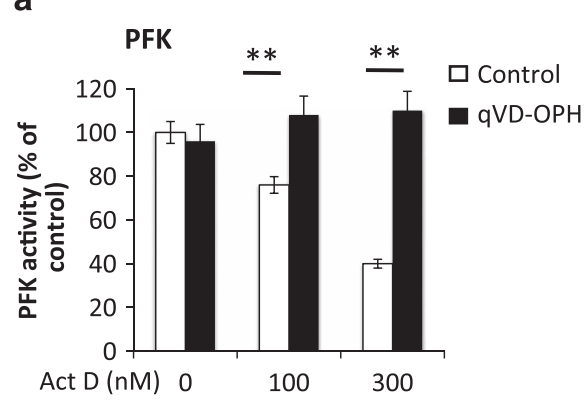

b

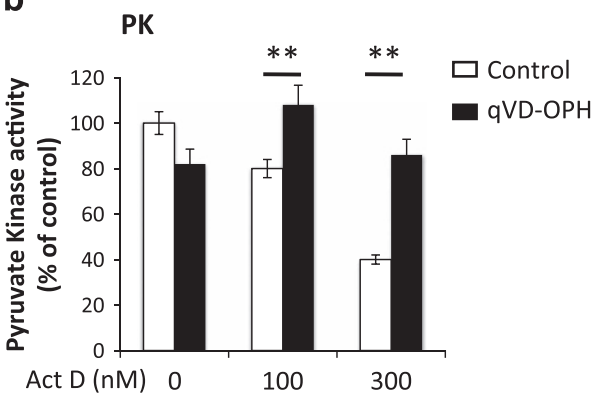

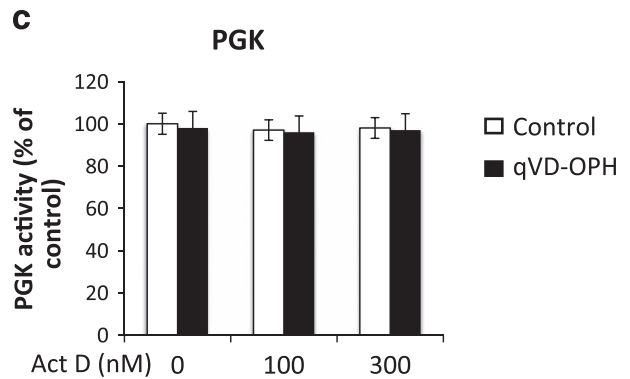

Figure 4 Caspases inhibit PFK and PK but not PGK activities. (a) PFK, (b) PK and (c) PGK activities in HeLa cells treated with the indicated amounts of actinomycin D for $16 \mathrm{~h}( \pm 20 \mu \mathrm{M}$ of qVD-OPH)

modulated during apoptosis, suggesting that the caspasedependent regulation of glycolysis occurred after PFK (Figures $5 \mathrm{~b}$ and 6). Furthermore, we observed that PEP decreased upon the induction of apoptosis, underscoring the role of caspases in the shutdown of this pathway. We also observed that $\alpha$-ketoglutarate was not modulated (Figure 5c), suggesting that the TCA cycle and/or the glutamine pathways were not significantly modulated by caspases. The same analysis revealed that the pentose phosphate (PP) pathway (Figure $5 d$ ) was not affected by caspases. This observation was confirmed by the absence of decrease in most nucleotides, which are produced at least in part by the PP pathway (Figures $5 f$ and 6). Interestingly, we observed that the levels of phospho-serine (P-Ser)-Ser were drastically decreased by caspases during apoptosis (Figure $5 \mathrm{e}$ ), altogether indicating that caspases impaired selective metabolic pathway during apoptosis.

\section{Discussion}

Our study suggested that caspases impaired glycolysis (Figures $3 a$ and $b$ ) and that this inhibition could result in decreased levels of cellular ATP during apoptosis. The caspase-dependent inhibition of glycolysis occurred between PFK and PK, as neither G6P nor F6P was modified upon the induction of apoptosis. We also tested whether one or more glycolytic enzymes were caspase substrates. Yet, despite numerous attempts and conditions tested, we could not repeatedly observe a caspase-dependent cleavage of several glycolytic enzymes (see Supplementary Figure 1). Therefore, it appears that caspases impair glycolysis, very likely, not through a direct cleavage of the glycolytic enzyme tested but rather through the cleavage of proteins that produce the intermediates required for the function of those enzymes. Furthermore, we observed that caspases lead to a decrease 

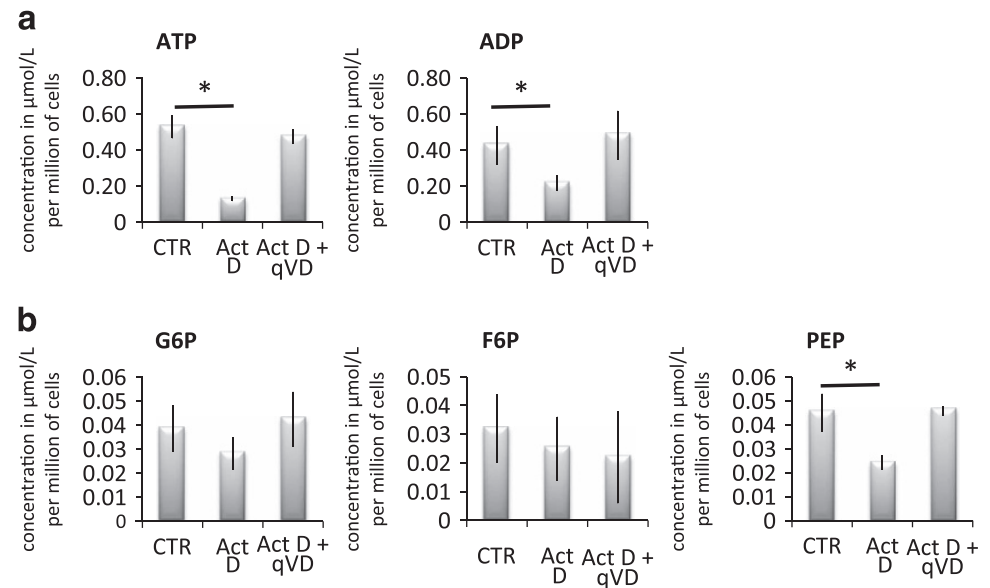

C
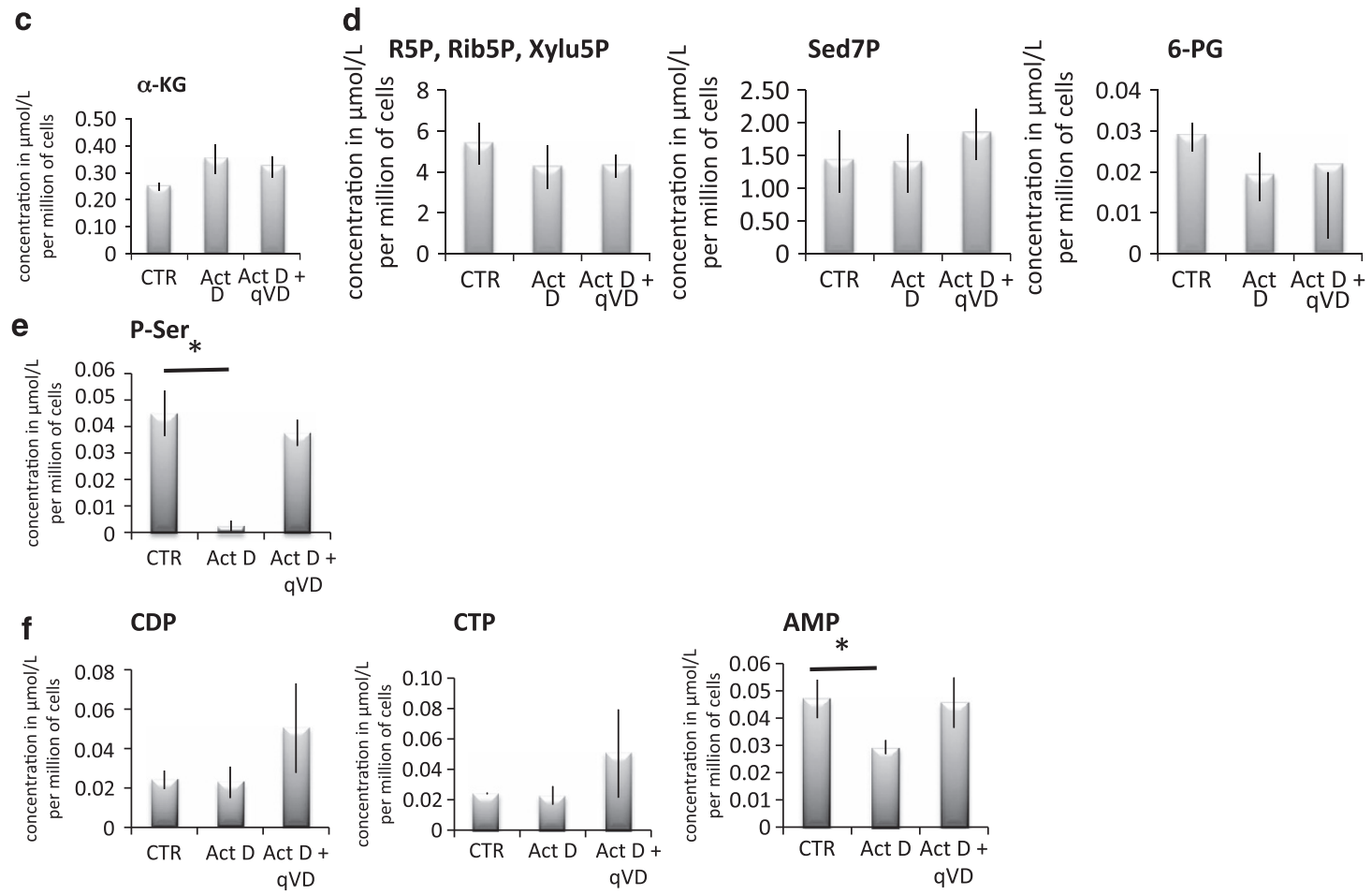

CTP
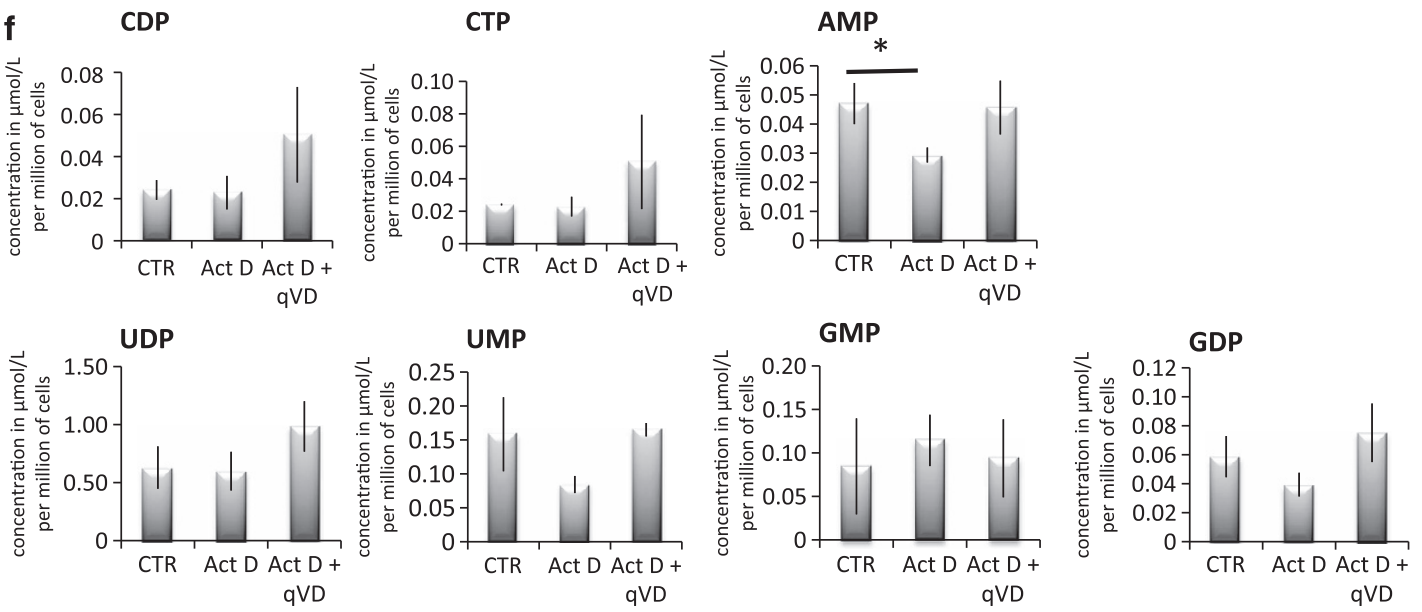

Figure 5 Caspase decreases the production of cellular ATP, PEP and P-serine during apoptosis. HeLa cells were treated with $1 \mu \mathrm{M}$ actinomycin D for $6 \mathrm{~h}$, at which time a metabolomic analysis of key glycolysis-related metabolites was performed. (a) ATP and ADP, (b) glycolytic products, (c) product of the TCA cycle, (d) products of the pentose phosphate pathway, (e) P-ser and (f) nucleotides intermediates measurements. Statistical analyses were performed for each metabolite between not treated (CTR) and actinomycin $\mathrm{D}$ conditions (Act D). ${ }^{*} P<0.05$; when not indicated, the differences did not reach significance; $\alpha$-KG, $\alpha$-ketoglutarate; 6 -PG, 6-phosphogluconic acid; R5P, ribose5-phosphate; Rib5P, ribulose 5-phosphat; Sed7P, sedoheptulose-7-phosphate; Xylu5P, xylulose 5-phosphate

in P-Ser, an intermediate in the serine pathway. As serine is a strong activator of $\mathrm{PK},{ }^{9}$ the reduction of $\mathrm{PK}$ activity could be due to the caspase-dependent cleavage of a key enzyme involved in the production of serine. The caspase-dependent cleavage of this enzyme would reduce serine production and therefore reduce PKM2 activity in apoptotic cells. 
However, this putative caspase substrate in the serine pathway has yet to be identified.

We observed a decrease in several glycolytic intermediates (Figures 3 and 6). As apoptosis can lead to secondary necrosis (i.e., rupture of the plasma membrane), one could argue that the decrease in those intermediates reflects a non specific loss due to nonspecific release from the cells. This effect seems very unlikely, as several intermediates were not modulated in our analysis, suggesting that caspases target specific metabolic pathways.

The decrease in ATP levels during apoptosis is a means by which caspases prevent any survival mechanism to occur. Without ATP, most enzyme reactions are suppressed, and the integrity of the cell membrane will eventually be lost. Indeed, the main consumers of ATP in the cell are membrane pumps that are essential for maintaining cell volume.

Moreover, ATP and UDP have been described to have important roles in the extracellular signaling of apoptotic cells. Indeed, these nucleotides are partially released into the extracellular medium during apoptosis to help attract the immune system. It has been shown that the types of immune cells recruited are different depending on the amount of released nucleotide. ${ }^{10,11}$ Thus, the caspase-dependent decrease of intracellular nucleotides during apoptosis could also influence nucleotide release into the extracellular medium and therefore modulate the immune response. For example, it has been shown that immune cells that are recruited to a necrotic site, characterized by a high concentration of ATP release from the cells, are different from those recruited to the apoptotic sites. ${ }^{11}$ Therefore, a better understanding of how caspases regulate cell metabolism will not only be of fundamental interest but could also help define ways to enhance the immune response against dying tumor cells.

\section{Materials and Methods}

Metabolomic analysis. Intracellular metabolites were analyzed as described previously. ${ }^{12,13}$ Briefly, the analysis was performed using high-performance anion exchange chromatography (Dionex ICS 2000 system, Dionex, Sunnyvale, CA, USA) coupled to a triple quadrupole QTrap 4000 (AB Sciex, Dublin, CA, USA) mass spectrometer. ${ }^{13}$ This analytical technology allows for the separation and analysis of numerous highly polar metabolites belonging to several chemical families in the same analytical run. All samples were analyzed in the negative mode by multiple reaction monitoring. The amounts of metabolites of glycolysis, PP pathways, the TCA cycle as well as nucleotides were determined. To ensure highly accurate quantification, the isotope dilution mass spectrometry method was used. ${ }^{14}$

Cell death measurement. After treatment, cells were resuspended in $200 \mathrm{ml}$ of buffer $(150 \mathrm{mM} \mathrm{NaCl}, 10 \mathrm{mM}$ HEPES, $5 \mathrm{mM} \mathrm{KCl}, 1 \mathrm{mM} \mathrm{MgCl}, 1.8 \mathrm{mM}$ $\mathrm{CaCl}_{2}$ ) and incubated with recombinant annexin $\mathrm{V}$-fluorescein isothiocyanate for

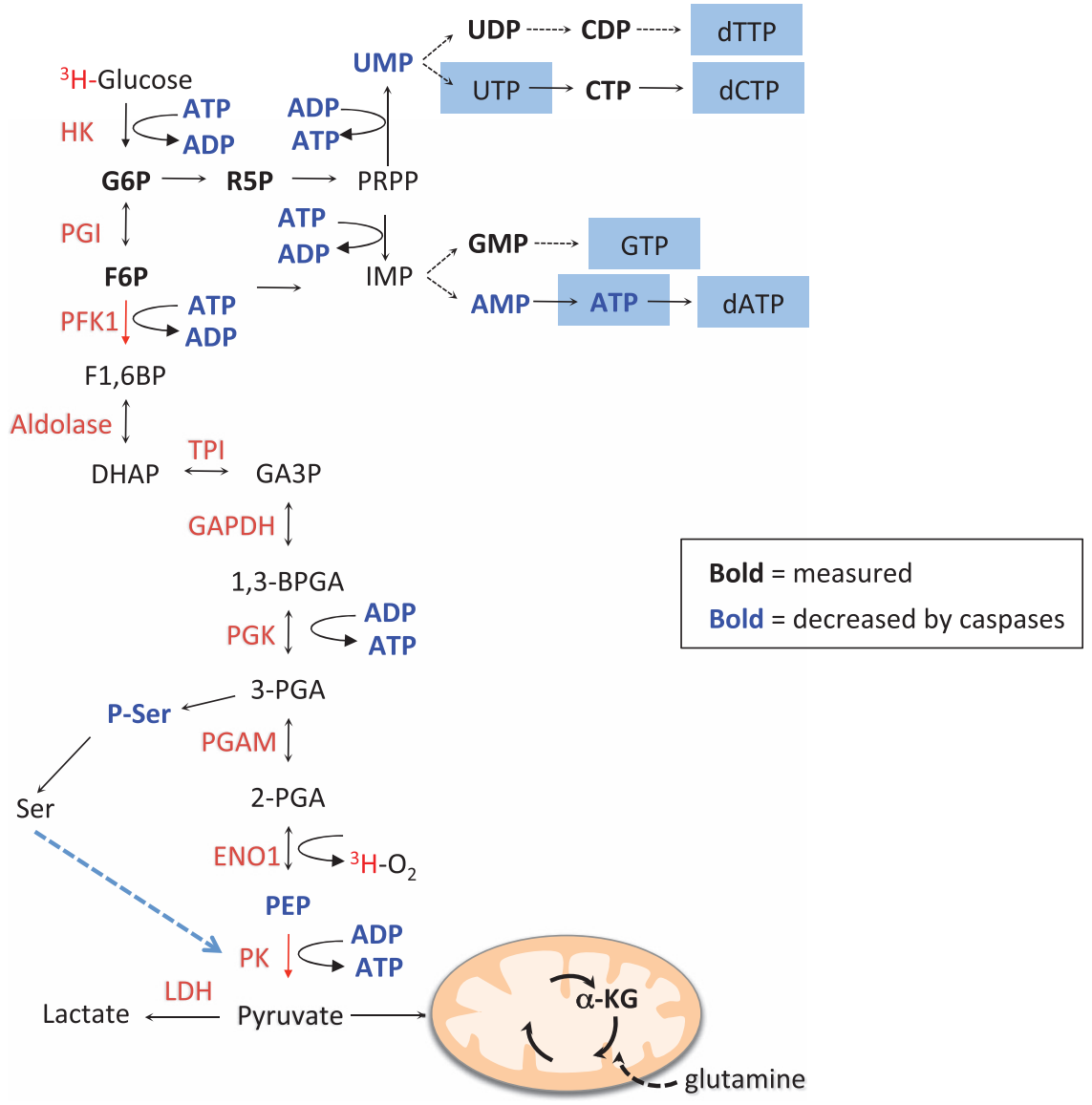

Figure 6 Schematic representation of the glycolysis pathway. Enzymes are indicated in red on the left side. Measured metabolites are presented in bold. Metabolites that decreased in a caspase-dependent manner are indicated in blue. ${ }^{3} \mathrm{H}$ indicates radiolabeled glucose leading to the generation of ${ }^{3} \mathrm{H}_{2} \mathrm{O} ; 1,3-\mathrm{BPGA}$, 1,3-bisphosphoglycerate; DHAP, dihydroxyacetone phosphate; ENO1, enolase 1; F1,6BP, fructose-1,6-bisphosphate; GA3P, glyceraldehyde 3-phosphate; IMP, inosine monophosphate; PGI, phosphoglucoisomerase; PGAM, phosphoglycerate mutase; 3-PGA,3-phosphoglycerate; PRPP, phosphoribosylpyrophosphate; TPI, triose phosphate isomerase 
$10 \mathrm{~min}$ at room temperature. A volume of $0.5 \mathrm{mg} / \mathrm{ml}$ of propidium iodide was then added, and samples were analyzed immediately by flow cytometry using a FACS (Miltenyi Biotec, Bergisch Gladbach, Germany). Percentage of apoptotic cells corresponds to annexin V-positive cells and annexin V/propidium iodide double-positive cells.

DEVDase activity. A total of $20 \mu \mathrm{g}$ of proteins (in triplicate) were incubated with $0.2 \mathrm{mM}$ of Ac-DEVD-AMC in $50 \mathrm{mM}$ HEPES pH 8; $150 \mathrm{mM} \mathrm{NaCl} ; 20 \mathrm{mM}$ ethylenediaminetetraacetic acid $\pm 1 \mu \mathrm{M}$ Ac-DEVD-CHO. Caspase activity was determined at $460 \mathrm{~nm}$, and specific activities were expressed in $\triangle O D$ per minute and per milligram of protein.

Measurement of glycolytic rate and lactate production. The rate of glucose metabolism by glycolysis was measured by following the conversion of 5 - ${ }^{3} \mathrm{H}$-glucose to ${ }^{3} \mathrm{H}_{2} \mathrm{O}$ as described previously. ${ }^{15,16}$ The ${ }^{3} \mathrm{H}$ on $\mathrm{C} 5$ of glucose is released in the form of ${ }^{3} \mathrm{H}_{2} \mathrm{O}$ during the second to last step of glycolysis, when 2-phosphoglycerate is converted to phosphoenolpyruvate by enolase. Briefly, cells were washed with phosphate-buffered saline before incubation in Krebs buffer without glucose for $30 \mathrm{~min}$ at $37^{\circ} \mathrm{C}$. The buffer was then replaced with $0.5 \mathrm{ml}$ of Krebs buffer containing $10 \mu \mathrm{Ci} 5{ }^{3} \mathrm{H}$-glucose in the presence of $10 \mathrm{mM}$ cold glucose and the cells were incubated for $1 \mathrm{~h}$ at $37^{\circ} \mathrm{C}$. The reaction was stopped by adding $0.1 \mathrm{ml}$ of $0.2 \mathrm{~N} \mathrm{HCl}$. Cell lysate $(0.2 \mathrm{ml})$ was transferred in duplicate into uncapped microtubes placed in a scintillation vial containing $0.5 \mathrm{ml}$ of water. The scintillation vial was then sealed to allow ${ }^{3} \mathrm{H}_{2} \mathrm{O}$ to evaporate from the microtube and condense in the $0.5 \mathrm{ml}$ of water in the bottom of the scintillation vial. ${ }^{3} \mathrm{H}_{2} \mathrm{O}$ will equilibrate between the cell lysate and the water in the scintillation vial over time. By contrast, ${ }^{3} \mathrm{H}$-glucose will not evaporate and will remain in the cell lysate. Therefore, the amount of ${ }^{3} \mathrm{H}_{2} \mathrm{O}$ generated was determined by diffusion after $48 \mathrm{~h}$ of incubation. Radioactivity was measured separately in the microtube and in the scintillation vial with a scintillation counter. The fraction of conversion of glucose into $\mathrm{H}_{2} \mathrm{O}$ (a.k.a. glycolytic rate) is calculated with the following formula: $F=\left(\right.$ activity $\left._{\text {vial }} / \mathrm{V} \mathrm{H}_{2} \mathrm{O}_{\text {vial }} \times \mathrm{V}_{\text {tube }}+\operatorname{activity}_{\text {vial }}\right) /\left(\right.$ activity $_{\text {tube }}+$ activity $\left._{\text {vial }}\right)$.

Lactate production was measured with the remaining $100 \mu \mathrm{l}$ of cell lysate using the lactate reagent from Trinity Biotech PIc (Bray, Co Wicklow, Ireland).

Glycolytic enzyme activity. The PGK, PK and PFK activities were measured with 5,20 and $50 \mu \mathrm{g}$ of protein, respectively, loaded in triplicate on a black 96-well plate (CellStar, Greiner Bio-One GmbH, Frickenhausen, Germany).

PGK activity was coupled with glyceraldehyde 3-phosphate dehydrogenase (GAPDH) activity NADH-dependent consumption (in the reverse way of glycolysis), whereas PK was coupled with LDH-dependent NADH consumption. PFK activity was coupled with PK and LDH-dependent NADH consumption. In this case, ADP produced by PFK is used by PK to generate PEP, which is then used as a substrate for $\mathrm{LDH}$ to consume NADH. For each assay, the appropriate amount of protein (in $10 \mu \mathrm{l}$ ) was incubated with the assay mixture $(90 \mu \mathrm{l})$; NADH levels were immediately measured at $445 \mathrm{~nm}$ over a 30 -min time period.

Reaction buffer for the PGK assay. $33 \mathrm{mM}$ 3-PGA, $1.1 \mathrm{mM}$ ATP, $5 \mathrm{U}$ $\mathrm{GAPDH}, 0.5 \mathrm{mM} \mathrm{NADH}, 83 \mathrm{mM}$ triethanolamine $\mathrm{pH} 7.4,2 \mathrm{mM} \mathrm{MgSO}{ }_{4}$ and $3 \mathrm{mM}$ L-cysteine. Mixture for the PFK assay: $74 \mathrm{mM}$ Tris $\mathrm{pH} 8.0,1.3 \mathrm{mM}$ $\mathrm{MgSO}_{4}, 4.5 \mathrm{mM} \mathrm{KCl}, 3.8 \mathrm{mM}$ fructose-6-phosphate, $0.65 \mathrm{mM}$ fructose-1, 6-bisphosphate, $1.3 \mathrm{mM}$ ATP, $0.97 \mathrm{mM}$ PEP, $0.5 \mathrm{mM} \mathrm{NADH}, 28 \mathrm{U}$ of recombinant $\mathrm{PK}$ and $40 \mathrm{U}$ of recombinant LDH.

Reaction buffer for the $P K$ assay. $6.8 \mathrm{mM} \mathrm{MgSO}_{4}, 9 \mathrm{mM} \mathrm{KH}_{2} \mathrm{PO}_{4}, 3 \mathrm{mM}$ PEP, $1.5 \mathrm{mM} \mathrm{ADP}$ and $10 \mathrm{U}$ of recombinant LDH.

\section{Conflict of Interest}

The authors declare no conflict of interest.
Acknowledgements. Metabolomics \& Fluxomics Facitilies, Toulouse, France (www.metatoul.fr) and its staff members (Lara Gales) are gratefully acknowledged for carrying out the metabolomic analyses. We thank Alice Baudot and Aurore Cornille for their help. This work was supported by the Fondation ARC (Association pour la Recherche sur le Cancer), the Agence Nationale de la Recherche (ANR-09JCJC-0003 and LABEX SIGNALIFE ANR-11-LABX-0028-01) and by la Fondation de France.

1. Pradelli LA, Beneteau M, Ricci JE. Mitochondrial control of caspase-dependent and independent cell death. Cell Mol Life Sci 2010; 67: 1589-1597.

2. Munoz-Pinedo C, El Mjiyad N, Ricci JE. Cancer metabolism: current perspectives and future directions. Cell Death Dis 2012; 3: e248.

3. Ros S, Schulze A. Balancing glycolytic flux: the role of 6-phosphofructo-2-kinase/fructose 2,6-bisphosphatases in cancer metabolism. Cancer Metab 2013; 1: 8.

4. Israelsen WJ, Dayton TL, Davidson SM, Fiske BP, Hosios AM, Bellinger G et al. PKM2 isoform-specific deletion reveals a differential requirement for pyruvate kinase in tumor cells. Cell 2013; 155: 397-409.

5. Galluzzi L, Kepp O, Vander Heiden MG, Kroemer G. Metabolic targets for cancer therapy. Nat Rev Drug Discov 2013; 12: 829-846.

6. Waterhouse NJ, Goldstein JC, von Ahsen O, Schuler M, Newmeyer DD, Green DR Cytochrome $\mathrm{c}$ maintains mitochondrial transmembrane potential and ATP generation after outer mitochondrial membrane permeabilization during the apoptotic process. $J$ Cell Biol 2001; 153: 319-328.

7. Navarro-Yepes J, Burns M, Anandhan A, Khalimonchuk O, Del Razo LM, Quintanilla-Vega B et al. Oxidative stress, redox signaling and autophagy: cell death vs survival. Antioxid Redox Signal 2014; 21: 66-85.

8. Ricci JE, Gottlieb RA, Green DR. Caspase-mediated loss of mitochondrial function and generation of reactive oxygen species during apoptosis. J Cell Biol 2003; 160: 65-75.

9. Chaneton B, Hillmann P, Zheng L, Martin AC, Maddocks OD, Chokkathukalam A et al. Serine is a natural ligand and allosteric activator of pyruvate kinase M2. Nature 2012; 491: 458-462.

10. Aymeric L, Apetoh L, Ghiringhelli F, Tesniere A, Martins I, Kroemer G et al. Tumor cell death and ATP release prime dendritic cells and efficient anticancer immunity. Cancer Res 2010; 70: 855-858.

11. Elliott MR, Chekeni FB, Trampont PC, Lazarowski ER, Kadl A, Walk SF et al. Nucleotides released by apoptotic cells act as a find-me signal to promote phagocytic clearance. Nature 2009; 461: 282-286.

12. Bolten CJ, Kiefer P, Letisse F, Portais JC, Wittmann C. Sampling for metabolome analysis of microorganisms. Anal Chem 2007; 79: 3843-3849.

13. Kiefer $P$, Nicolas $C$, Letisse F, Portais JC. Determination of carbon labeling distribution of intracellular metabolites from single fragment ions by ion chromatography tandem mass spectrometry. Anal Biochem 2007; 360: 182-188.

14. Wu L, Mashego MR, van Dam JC, Proell AM, Vinke JL, Ras C et al. Quantitative analysis of the microbial metabolome by isotope dilution mass spectrometry using uniformly 13C-labeled cell extracts as internal standards. Anal Biochem 2005; 336: 164-171.

15. Vander Heiden MG, Plas DR, Rathmell JC, Fox CJ, Harris MH, Thompson CB. Growth factors can influence cell growth and survival through effects on glucose metabolism. Mol Cell Biol 2001; 21: 5899-5912.

16. Zhao Y, Wieman HL, Jacobs SR, Rathmell JC. Mechanisms and methods in glucose metabolism and cell death. Methods Enzymol 2008; 442: 439-457.

Cell Death and Disease is an open-access journal published by Nature Publishing Group. This work is licensed under a Creative Commons Attribution-NonCommercialNoDerivs 3.0 Unported License. The images or other third party material in this article are included in the article's Creative Commons license, unless indicated otherwise in the credit line; if the material is not included under the Creative Commons license, users will need to obtain permission from the license holder to reproduce the material. To view a copy of this license, visit http://creativecommons.org/licenses/ by-nc-nd/3.0/ 